\title{
Photoluminescence of Red-Emitting Phosphor Sr2CeO4: Eu3+, Sm3+ for Light-Emitting Diodes
}

\author{
Haiyan Jiao ${ }^{1, a^{*}}$, Cairang LiMao ${ }^{1, b}$, Rangcuo Cai ${ }^{1, c}$ \\ ${ }^{1}$ Key Laboratory for Electronic Materials of the State National Affairs Commission of PRC, \\ Northwest University for Nationalities, Lanzhou 730030, China \\ adqjhy@xbmu.edu.cn, ${ }^{\text {b}} 115416333 @ q q . c o m,{ }^{c} 825081869 @ q q . c o m$
}

Keywords: Optical materials; Rare earth ions; Luminescence properties; White LEDs

\begin{abstract}
The red-emitting phosphor Sr2CeO4: Eu3+, Sm3+ was synthesized by conventional high-temperature solid-state method. X-ray diffraction, and photoluminescence spectra were used to characterize the as-synthesized phosphor. In Eu3+ singly doped $\mathrm{Sr} 2 \mathrm{CeO} 4$ phosphors, Eu3+ ion showed a weaker 7F0-5L6 transition at $395 \mathrm{~nm}$ with a narrow line and could not be efficiently excited by the NUV-LED chip. In Sm3+, Eu3+ co-doped $\mathrm{Sr} 2 \mathrm{CeO} 4$ phosphors, the energy transfer from $\mathrm{Sm} 3+$ to $\mathrm{Eu} 3+$ in $\mathrm{Sr} 2 \mathrm{CeO} 4$ host is observed and investigated in detail. The absorption band around $404 \mathrm{~nm}$ was broadened and the intensities of the main emission line $(5 \mathrm{D} 0 \rightarrow 7 \mathrm{~F} 2$ transition of Eu3 + at $614 \mathrm{~nm}$ ) were strengthened because the energy transfer from $\mathrm{Sm} 3+$ to Eu3+. Moreover, The chromaticity coordinates of $\mathrm{Sr} 2 \mathrm{CeO} 4: \mathrm{Sm} 3+$ can be regulated to approach the NTSC standard values of red phosphor by codoping Eu3+ ions. The photoluminescence properties suggest that novel $\mathrm{Sr} 2 \mathrm{CeO} 4: \mathrm{Eu} 3+, \mathrm{Sm} 3+$ phosphor might have a potential research value on white-LEDs.
\end{abstract}

\section{Introduction}

In recent years, White light-emitting diodes (W-LEDs) have been called as the new generation of solid state lighting source with its long lifetime, low energy consumption, Small volume, high luminescence efficiency and environmental-friendly characteristics[1,2]. The most general strategy of producing white light is to employ the yellow phosphor YAG:Ce ${ }^{3+}$ with the blue LED chips [3]. However, due to the lack of a sufficient red emission component in the visible spectrum, this combination leads to low color-rendering index (CRI) and high correlated color temperature (CCT), which limited their potential applications [4]. With the development of chip technology, alternatively, another the commonly method is coating the near ultraviolet (NUV) LED or UV-LED chips with the primary tricolor (RGB) multi-phased phosphors [5]. Unfortunately, some problems also appear. Such a multi-phosphors combination, leading to decreased luminous efficiency due to reabsorption of different emission colors [6]. Moreover, the efficiency of $\mathrm{Y}_{2} \mathrm{O}_{2} \mathrm{~S}: \mathrm{Eu}^{3+}$ red phosphor among the tricolor multi-phased phosphors is much lower than that of the green and blue phosphors. In addition, the lifetime of the $\mathrm{Y}_{2} \mathrm{O}_{2} \mathrm{~S}: \mathrm{Eu}^{3+}$ is inadequate under NUV irradiation for its instability $[7,8]$. Consequently, it is urgent to search for novel and highly efficient red phosphors that can be excited by NUV (350 -420 nm).

A suitable red-emitting NUV-LED phosphor should meet the following necessary conditions in general: the host is stable, the phosphor exhibits strong and broad absorption around $\sim 400 \mathrm{~nm}$, which matches well with the radiation of NUV-LED chip, and the phosphor shows high efficiency under NUV excitation and with the chromaticity coordinates near the NTSC (National Television Standard Committee) Standard values.

In order to search for red-emitting phosphors with high efficiency and proper CIE chromaticity coordinates, the $\mathrm{Eu}^{3+}$-activated phosphors are primarily considered. The trivalent europium ion is well-known as a red-emitting activator due to its particular spectral character [9-11]. In the past work, We have already reported $\mathrm{Eu}^{3+}$ ion doped $\mathrm{Sr}_{2} \mathrm{CeO}_{4}$ due to their absorption band around $395 \mathrm{~nm}$, which matches with the radiation of NUV-LED chip [12]. However, in $\mathrm{Sr}_{2} \mathrm{CeO}_{4}: \mathrm{Eu}^{3+}$ system, $\mathrm{Eu}^{3+}$ ion showed a weaker ${ }^{7} \mathrm{~F}_{0}-{ }^{5} \mathrm{~L}_{6}$ transition at $395 \mathrm{~nm}$ with a narrow line and could not be efficiently excited 
by the NUV-LED chip. In order to strengthen and broaden the absorption around $\sim 400 \mathrm{~nm}$, one of the effective method is introduced a co-doped ions as an activator in the phosphors. The $\mathrm{Sm}^{3+}$ ion has been widely used as an activator of reddish orange emission and its efficient absorption band of NUV is at around $405 \mathrm{~nm}$, which is in good agreement with the absorption peak $\left({ }^{6} \mathrm{H}_{5 / 2} \rightarrow{ }^{4} \mathrm{~K}_{11 / 2}\right)$ of $\mathrm{Sm}^{3+}$. Hence, $\mathrm{Sm}^{3+}$ ions are expected to be ideal activator for red phosphor for NUV-LEDs. Accordingly, In $\mathrm{Sm}^{3+}, \mathrm{Eu}^{3+}$ co-doped phosphors system, through the energy transfer from $\mathrm{Sm}^{3+}$ to $\mathrm{Eu}^{3+}$ maybe enhance the absorption band around $400 \mathrm{~nm}$, which have been confirmed in molybdate system [13, $14]$.

Therefore, In this paper, we synthesized $\mathrm{Sm}^{3+}$ and $\mathrm{Eu}^{3+}$ co-doped $\mathrm{Sr}_{2} \mathrm{CeO}_{4}$ phosphors and investigated the co-doped effects of $\mathrm{Sm}^{3+}$ ions on the luminescence properties for $\mathrm{Sr}_{2} \mathrm{CeO}_{4}$ : $\mathrm{Eu}^{3+}$ phosphor and found that $\mathrm{Sr}_{2} \mathrm{CeO}_{4}: \mathrm{Sm}^{3+}, \mathrm{Eu}^{3+}$ phosphor might be a potential red phosphor for NUV-LEDs.

\section{Experimental}

A series of $\mathrm{Sr}_{2-\mathrm{x}-\mathrm{y}} \mathrm{CeTi}_{\mathrm{x}} \mathrm{O}_{4}: \mathrm{xEu}^{3+}, \mathrm{ySm}^{3+}$ phosphor samples with different concentrations of $\mathrm{Eu}^{3+}$ and $\mathrm{Sm}^{3+}$ were synthesized by a high temperature solid-state method. The starting materials $\mathrm{SrCO}_{3}(99 \%)$, $\mathrm{CeO}_{2}$ (99.99\%), $\mathrm{TiO}_{2}$ (99\%), $\mathrm{Sm}_{2} \mathrm{O}_{3}(99.99 \%)$ and $\mathrm{Eu}_{2} \mathrm{O}_{3}$ (99.99\%) were weighed according to appropriate stoichiometric ratio and ground evenly in agate mortar. A proper amount of $\mathrm{H}_{3} \mathrm{BO}_{3}$ $(99.5 \%)$ was added to serve as flux. Then the homogeneous mixture obtained was put into an alumina crucible and calcined in a muffle furnace at the temperature of $1200^{\circ} \mathrm{C}$ for $6 \mathrm{~h}$, and finally the sample was ground thoroughly into powder for measurement after being cooled down to room temperature.

The phase purity of prepared samples were performed on a Rigaku D/MAX-2400 powder X-ray diffractometer $(\mathrm{XRD})$ with Ni-filtered $\mathrm{Cu} \mathrm{K \alpha}$ radiation $(\lambda=1.54178 \AA)$ operated at $40 \mathrm{kV}$ and $60 \mathrm{~mA}$. The $2 \theta$ ranges from $10 \sim 80^{\circ}$ with the scanning step of $0.02^{\circ}$. The emission and excitation spectra were recorded using an FLS-920T fluorescence spectrophotometer equipped with a 450W Xe light source. The CIE chromaticity coordinates of all samples were calculated by "ZolixColorConvert 1.0" program (Beijing Zolix Instruments Co., Ltd.). All the measurements were performed at room temperature.

\section{Results and Disdussion}

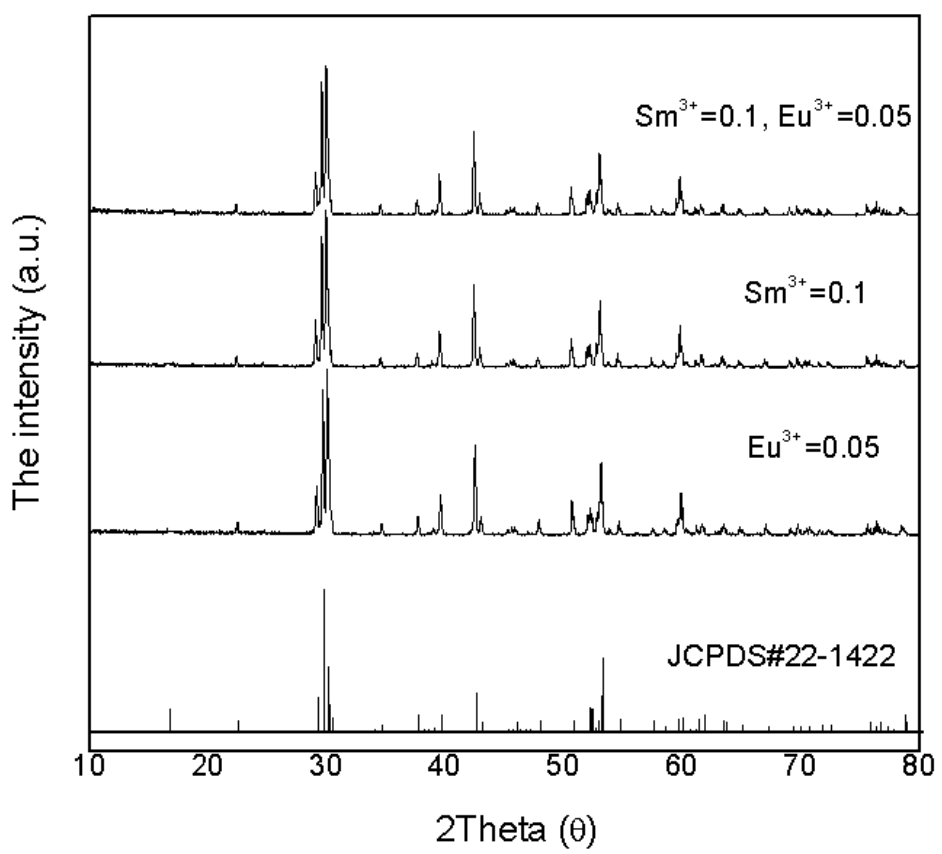

Figure 1. The XRD patterns of $\mathrm{Sr}_{1.95} \mathrm{CeO}_{4}: 0.05 \mathrm{Eu}^{3+}, \mathrm{Sr}_{1.9} \mathrm{CeO}_{4}: 0.1 \mathrm{Sm}^{3+}$ and $\mathrm{Sr}_{1.85} \mathrm{CeO}_{4}$ : $0.05 \mathrm{Eu}^{3+}, 0.1 \mathrm{Sm}^{3+}$ samples. The standard data of $\mathrm{Sr}_{2} \mathrm{CeO}_{4}$ (JCPDS NO.22-1422). 
In order to characterize the phase purity and crystallinity of the as-prepared powder samples, the XRD patterns for all samples were examined. The XRD patterns of $\mathrm{Sr}_{1.95} \mathrm{CeO}_{4}$ : $0.05 \mathrm{Eu}^{3+}, \mathrm{Sr}_{1.9} \mathrm{CeO}_{4}$ : $0.1 \mathrm{Sm}^{3+}$ and $\mathrm{Sr}_{1.85} \mathrm{CeO}_{4}: 0.05 \mathrm{Eu}^{3+}, 0.1 \mathrm{Sm}^{3+}$ samples are shown in Fig. 1. All of the diffraction peaks were found to be well matched with the JCPDS no. 22-1422, which indicates that no impurity phase is present and the $\mathrm{Sr}^{2+}$ can be partly replaced by $\mathrm{Eu}^{3+}$ and $\mathrm{Sm}^{3+}$ without change of crystal structure. Besides, the XRD patterns for all other samples are the same and no extra diffraction peaks are observed in this paper. Substitution of the $\mathrm{Ca}^{2+}$ sites with the trivalent rare-earth ions $\mathrm{Eu}^{3+}\left(\mathrm{Sm}^{3+}\right)$ results in a positive charge $\operatorname{Re}_{C a}^{\cdot}$ in the lattice. In general, according to the Kröger - Vink defect notation [15], the positive charges can be compensated by either cation vacancies $V_{M}^{\prime \prime}$, or oxygen

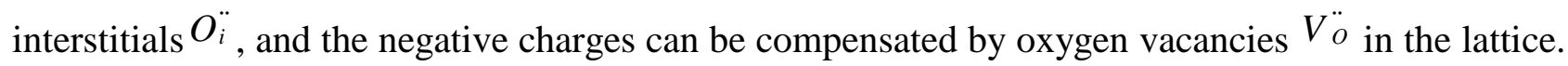
In this case, extra positive charge $\mathrm{Eu}_{C a}\left(\mathrm{Sm}_{C a}^{\cdot}\right)$, can be compensated by the lattice calcium ion vacancy in $\mathrm{Sr}_{2} \mathrm{CeO}_{4}: \mathrm{Eu}^{3+}\left(\mathrm{Sm}^{3+}\right)$.

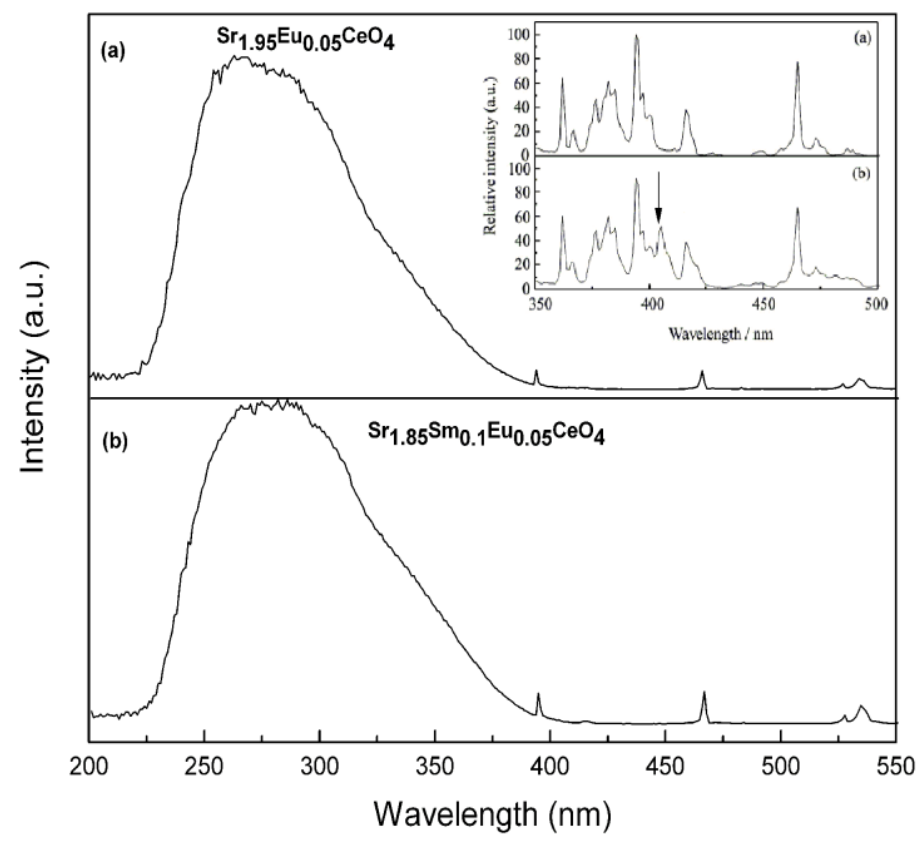

Figure 2. (a) The excitation spectra of $\mathrm{Sr}_{1.95} \mathrm{CeO}_{4}: 0.05 \mathrm{Eu}^{3+}\left(\lambda_{\text {em }}=614 \mathrm{~nm}\right)$; (b) The excitation spectra of $\mathrm{Sr}_{1.85} \mathrm{CeO}_{4}: 0.05 \mathrm{Eu}^{3+}, 0.1 \mathrm{Sm}^{3+}\left(\lambda_{\mathrm{em}}=614 \mathrm{~nm}\right)$. (The inserted figure shows the $350 \sim 500 \mathrm{~nm}$ enlarged excitation spectra)

The photoluminescence properties of $\mathrm{Sr}_{2} \mathrm{CeO}_{4}: \mathrm{Eu}^{3+}$ and $\mathrm{Sr}_{2} \mathrm{CeO}_{4}: \mathrm{Eu}^{3+}, \mathrm{Sm}^{3+}$ phosphors were measured. Fig. 2 presents that the excitation spectrum of (a) $\mathrm{Sr}_{1.95} \mathrm{CeO}_{4}: 0.05 \mathrm{Eu}^{3+}$ and (b) $\mathrm{Sr}_{1.85} \mathrm{CeO}_{4}$ : $0.05 \mathrm{Eu}^{3+}, 0.1 \mathrm{Sm}^{3+}$ phosphors monitored with the $614 \mathrm{~nm}$ emission consists of a broad band with a maximum at $289 \mathrm{~nm}$ and some sharp lines between 350 and $550 \mathrm{~nm}$ at room temperature. The broad band centered at $289 \mathrm{~nm}$ is assigned to the contribution of charge transfer (CT) transition from oxygen to cerium $\left(\mathrm{O}^{2-} \rightarrow \mathrm{Ce}^{4+}\right)$, the sharp peaks ranging from $340 \mathrm{~nm}$ to $450 \mathrm{~nm}$ corresponding to the $\mathrm{f}-\mathrm{f}$ transitions of $\mathrm{Eu}^{3+}$ and $\mathrm{Sm}^{3+}$ ions. Among them, relative to the broadband excitation, the $\mathrm{f}-\mathrm{f}$ transition absorption peaks are very weak, it's almost impossible to observe. Therefore, the inserted figure shows the $350 \sim 500 \mathrm{~nm}$ enlarged excitation spectra of (a) $\mathrm{Sr}_{1.95} \mathrm{CeO}_{4}: 0.05 \mathrm{Eu}^{3+}$ and (b) $\mathrm{Sr}_{1.85} \mathrm{CeO}_{4}: 0.05 \mathrm{Eu}^{3+}, 0.1 \mathrm{Sm}^{3+}$ phosphors. We could see that the most strongest excitation peak at $394 \mathrm{~nm}\left({ }^{7} \mathrm{~F}_{0^{--}}{ }^{5} \mathrm{~L}_{6}\right.$ transition of $\left.\mathrm{Eu}^{3+}\right)$ and the stronger peak at $466 \mathrm{~nm}\left({ }^{7} \mathrm{~F}_{0^{--}}{ }^{5} \mathrm{D}_{2}\right.$ transition of $\left.\mathrm{Eu}^{3+}\right)$. As shown in the inset of Fig. 2(b), In the case of $\mathrm{Sr}_{1.85} \mathrm{CeO}_{4}: 0.05 \mathrm{Eu}^{3+}, 0.1 \mathrm{Sm}^{3+}$, the excited band about $400 \mathrm{~nm}$ was broaden and enhanced because of a extra small sharp excitation peak at $404 \mathrm{~nm}$ $\left({ }^{6} \mathrm{H}_{5 / 2^{--}}{ }^{4} \mathrm{~F}_{7 / 2}\right.$ transition of $\left.\mathrm{Sm}^{3+}\right)$, these wavelength make the excitation intensity during NUV 
relatively strong and make the phosphors suitable to be used for NUV excitation. Therefore, $\mathrm{Sm}^{3+}$, $\mathrm{Eu}^{3+}$ co-doped $\mathrm{Sr}_{2} \mathrm{CeO}_{4}$ phosphors is suitable for NUV light wavelength conversion phosphors.

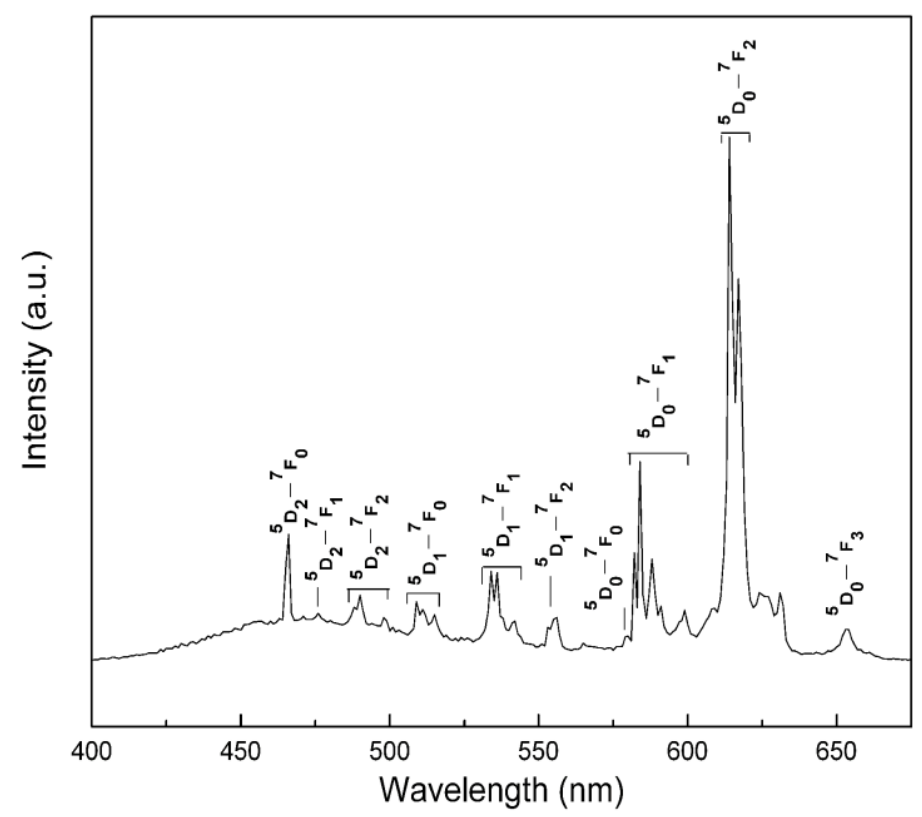

Figure 3. The Emission spectra of $\mathrm{Sr}_{1.85} \mathrm{CeO}_{4}: 0.05 \mathrm{Eu}^{3+}, 0.1 \mathrm{Sm}^{3+}\left(\lambda_{\mathrm{ex}}=394 \mathrm{~nm}\right)$

Fig. 3 shows the emission spectrum of $\mathrm{Sr}_{1.85} \mathrm{CeO}_{4}: 0.05 \mathrm{Eu}^{3+}, 0.1 \mathrm{Sm}^{3+}$ phosphor excited at $394 \mathrm{~nm}$. From the emission spectra, we could see that there is no emission peak of $\mathrm{Sm}^{3+}$ in the emission spectrum, which is mainly the characteristic emission of $\mathrm{Eu}^{3+}$. The emission spectrum of $\mathrm{Sr}_{1.85} \mathrm{CeO}_{4}$ : $0.05 \mathrm{Eu}^{3+}, 0.1 \mathrm{Sm}^{3+}$ is composed of characteristic emission of $\mathrm{Eu}^{3+}$ intra- $4 \mathrm{f}^{6}$ sharp lines in the blue, green and red regions, they are assigned to the transitions between the ${ }^{5} \mathrm{D}_{0},{ }^{5} \mathrm{D}_{1}$ and ${ }^{5} \mathrm{D}_{2}$ excited states and ${ }^{7} \mathrm{~F}_{0-3}$ ground states. Among all the emission transitions, the hypersensitive electric dipole transition at $614 \mathrm{~nm}\left({ }^{5} \mathrm{D}_{0} \rightarrow{ }^{7} \mathrm{~F}_{2}\right)$ was found to be prominent, but other characteristic transitions show the weaker spectral lines. In general, the existence of such a transition from higher levels $\left({ }^{5} \mathrm{D}_{1}\right.$, ${ }^{5} \mathrm{D}_{2}$ )depends on the type of matrix lattice. Usually, it is difficult to observe the transition emission from excited state ${ }^{5} \mathrm{D}_{2},{ }^{5} \mathrm{D}_{1}$, this is because among all the excited state of $\mathrm{Eu}^{3+}$ ion, the energy gaps between two neighboring ${ }^{5} \mathrm{D}_{2},{ }^{5} \mathrm{D}_{1},{ }^{5} \mathrm{D}_{0}$ excited state levels is relatively small, $\Delta \mathrm{E}_{1}\left({ }^{5} \mathrm{D}_{2^{--}}{ }^{5} \mathrm{D}_{1}\right) \approx$ $2300 \mathrm{~cm}^{-1}, \Delta \mathrm{E}_{1}\left({ }^{5} \mathrm{D}_{1}-{ }^{-5} \mathrm{D}_{0}\right) \approx 1733 \mathrm{~cm}^{-1}[16]$. It is easily that efficient electrons relaxation from higher ${ }^{5} \mathrm{D}_{2}$ and ${ }^{5} \mathrm{D}_{1}$ excited states levels to the lower ${ }^{5} \mathrm{D}_{0}$ level and emit characteristic light of ${ }^{5} \mathrm{D}_{0}$ excited states. It is reported that $\mathrm{Sr}_{2} \mathrm{CeO}_{4}$ is a special kind of matrix, and its maximum vibration frequency of lattice is lower $\left(<600 \mathrm{~cm}^{-1}\right)[17,18]$. When the $\mathrm{Eu}^{3+}$ is doped, the lower lattice vibrational energy is not enough to fully couple the transition from ${ }^{5} \mathrm{D}_{1}$ to ${ }^{5} \mathrm{D}_{0}$, so the transition emission of higher ${ }^{5} \mathrm{D}_{1}$ excited state energy appears. Table1 gives the specific attribution of emission peaks in emission spectra. The dominating emissions peak is around at $614 \mathrm{~nm}$ corresponding to the transitions ${ }^{5} \mathrm{D}_{0} \rightarrow{ }^{7} \mathrm{~F}_{2}$ of Eu ${ }^{3+}$ ion. In addition, From the emission spectra of $\mathrm{Eu}^{3+}$ and $\mathrm{Sm}^{3+}$ co-doped sample, we could see that there is no emission peak of $\mathrm{Sm}^{3+}$ in the emission spectrum, which is mainly the characteristic emission of $\mathrm{Eu}^{3+}$. The preliminary analysis is that there is a certain energy transfer between $\mathrm{Sm}^{3+}$ and $\mathrm{Eu}^{3+}$.

In order to further show that there is a energy transfer in $\mathrm{Eu}^{3+}$ and $\mathrm{Sm}^{3+}$ co-doped sample, we analyzed the emission spectrum under $404 \mathrm{~nm}$ excitation. From the excitation spectrum of $\mathrm{Sr}_{1.85} \mathrm{CeO}_{4}$ : $0.05 \mathrm{Eu}^{3+}, 0.1 \mathrm{Sm}^{3+}$ (in the inserted Fig. 2(b)), it is found that a extra small sharp excitation peak at 404 $\mathrm{nm}\left({ }^{6} \mathrm{H}_{5 / 2^{--}}{ }^{4} \mathrm{~F}_{7 / 2}\right.$ transition of $\left.\mathrm{Sm}^{3+}\right)$. Therefore, we measured the emission spectra of $\mathrm{Sr}_{1.85} \mathrm{CeO}_{4}$ : $0.05 \mathrm{Eu}^{3+}, 0.1 \mathrm{Sm}^{3+}$ and $\mathrm{Sr}_{1.95} \mathrm{CeO}_{4}: 0.05 \mathrm{Eu}^{3+}$ under $404 \mathrm{~nm}$ excitation, which the emission spectrum are similar to that of the emission spectrum under the excitation of $394 \mathrm{~nm}$ (in Fig. 3 ). In $\mathrm{Eu}^{3+}$ and $\mathrm{Sm}^{3+}$ co-doped sample, the emission spectra under $404 \mathrm{~nm}$ excitation is the same as that of the $\mathrm{Eu}^{3+}$ single doped sample, indicating that the co-doped sample can be excited efficiently by $404 \mathrm{~nm}$ 
corresponding to the ${ }^{6} \mathrm{H}_{5 / 2}-{ }^{4} \mathrm{~F}_{7 / 2}$ transition of $\mathrm{Sm}^{3+}$ ion, the emission from Characteristic transitions of $\mathrm{Eu}^{3+}$ is also observed. This can be considered as a clear evidence of energy transfer from $\mathrm{Sm}^{3+}$ to $\mathrm{Eu}^{3+}$ ion. The relative emission intensity of the $\mathrm{Eu}^{3+} / \mathrm{Sm}^{3+}$ co-doped systems at $614 \mathrm{~nm}$ is about 3 times that of the $\mathrm{Eu}^{3+}$ single-doped systems. It states that the $\mathrm{Sm}^{3+}$ ions can absorb and transfer energy to $\mathrm{Eu}^{3+}$ ions efficiently.

Table1 Attribution of $\mathrm{Eu}^{3+}$ emission peaks in phosphor of $\mathrm{Sr}_{1.85} \mathrm{CeO}_{4}: 0.05 \mathrm{Eu}^{3+}, 0.1 \mathrm{Sm}^{3+}$

\begin{tabular}{|c|c||c|c|}
\hline Emission peak/ nm & Attribution & Emission peak/nm & Attribution \\
\hline 466 & ${ }^{5} \mathrm{D}_{2-}{ }^{7} \mathrm{~F}_{0}$ & 556 & ${ }^{5} \mathrm{D}_{1-}{ }^{7} \mathrm{~F}_{2}$ \\
\hline 490 & ${ }^{5} \mathrm{D}_{2}{ }^{7} \mathrm{~F}_{2}$ & 584 & ${ }^{5} \mathrm{D}_{0-}{ }^{7} \mathrm{~F}_{1}$ \\
\hline 509 & ${ }^{5} \mathrm{D}_{1}{ }^{7} \mathrm{~F}_{0}$ & 614 & ${ }^{5} \mathrm{D}_{0}{ }^{7} \mathrm{~F}_{2}$ \\
\hline 534 & ${ }^{5} \mathrm{D}_{1}{ }^{7} \mathrm{~F}_{1}$ & 653 & ${ }^{5} \mathrm{D}_{0}{ }^{7} \mathrm{~F}_{3}$ \\
\hline
\end{tabular}

A simple model of the process of the energy transfer from $\mathrm{Sm}^{3+}$ to $\mathrm{Eu}^{3+}$ is illustrated in Fig. 4. Under the excitation of $404 \mathrm{~nm}, \mathrm{Sm}^{3+}$ in the ground state $\left({ }^{6} \mathrm{H}_{5 / 2}\right)$ are excited to the excitd state $\left({ }^{4} \mathrm{~F}_{7 / 2}\right)$, and then the non-radiatively relaxation of the ${ }^{4} \mathrm{G}_{5 / 2}$ level is populated. Some of the excited $\mathrm{Sm}^{3+}$ ions act as sensitizers to transfer their energy to $\mathrm{Eu}^{3+}$ ions. As a result, the $\mathrm{Eu}^{3+}$ ions are sensitized to show the characteristic emissions of ${ }^{5} \mathrm{D}_{0} \rightarrow{ }^{7} \mathrm{~F}_{2}$ transition, which gives rise to red visible light. The reason why $\mathrm{Sm}^{3+} \rightarrow \mathrm{Eu}^{3+}$ energy transfer occurs is that the ${ }^{4} \mathrm{G}_{5 / 2}$ level of the lowest excited state energy level of $\mathrm{Sm}^{3+}$ is $600 \mathrm{~cm}^{-1}$ higher than that of $\mathrm{Eu}^{3+}\left({ }^{5} \mathrm{D}_{0}\right)$. Therefore, through the energy transfer of $\mathrm{Sm}^{3+} \rightarrow$ $\mathrm{Eu}^{3+}$, the ${ }^{5} \mathrm{D}_{0^{-}}{ }^{7} \mathrm{~F}_{2}$ emission of $\mathrm{Eu}^{3+}$ is obviously enhanced.

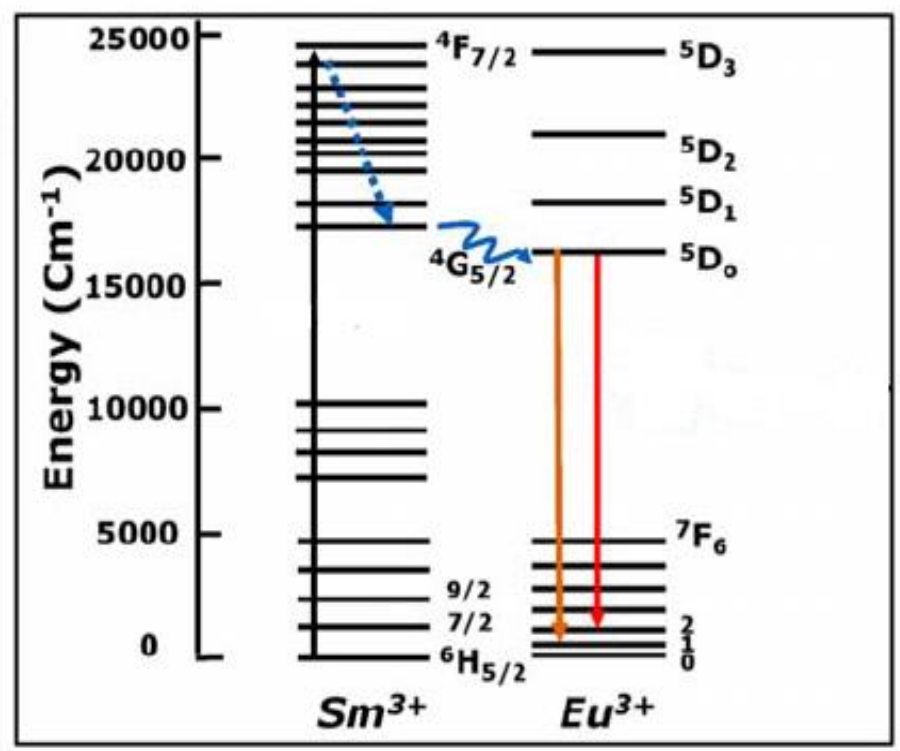

Figure 4. Energy level diagram of $\mathrm{Eu}^{3+} / \mathrm{Sm}^{3+}$ single and schematic diagram of $\mathrm{Sm}^{3+}-\mathrm{Eu}^{3+}$ energy transfer process in $\mathrm{Sr}_{2} \mathrm{CeO}_{4}$ phosphors.

On the whole, the luminous efficiency of $\mathrm{Sr}_{1.85} \mathrm{CeO}_{4}: 0.05 \mathrm{Eu}^{3+}, 0.1 \mathrm{Sm}^{3+}$ phosphor under the excitation of $404 \mathrm{~nm}$ was obviously improved, which is about 3 times of that of the single doped $\mathrm{Sr}_{1.95} \mathrm{CeO}_{4}: 0.05 \mathrm{Eu}^{3+}$. The CIE chromaticity coordinates of $\mathrm{Sr}_{1.85} \mathrm{CeO}_{4}: 0.05 \mathrm{Eu}^{3+}, 0.1 \mathrm{Sm}^{3+}$ phosphor is calculated as $(0.65,0.32)$ by "Zolix Color Convert" program, which is closer to the NTSC standard red light values of $(0.67,0.33)$. These results showed that the $\mathrm{Sr}_{2} \mathrm{CeO}_{4}: \mathrm{Eu}^{3+}, \mathrm{Sm}^{3+}$ phosphor could be used as a candidate material for NUV-LED with red phosphors. 


\section{Conclusions}

In summary, a novel red-emitting phosphor $\mathrm{Sr}_{2} \mathrm{CeO}_{4}: \mathrm{Eu}^{3+}, \mathrm{Sm}^{3+}$ has been prepared by conventional high-temperature solid-state method. The X-ray diffraction, photoluminescence properties were investigated in detail. For the $\mathrm{Eu}^{3+} / \mathrm{Sm}^{3+}$ exhibits strong absorption at $395 \mathrm{~nm} / 405 \mathrm{~nm}$ in many matrices, double doped phosphors $\mathrm{Sr}_{2} \mathrm{CeO}_{4}: \mathrm{Eu}^{3+}, \mathrm{Sm}^{3+}$ not only broaden and enhance the absorption band at $\sim 400 \mathrm{~nm}$, but also because of the energy transfer from $\mathrm{Sm}^{3+}$ to $\mathrm{Eu}^{3+}$, the luminous efficiency of phosphor is greatly improved. Under the excitation of NUV, the luminescence intensity of the phosphor $\mathrm{Sr}_{1.85} \mathrm{CeO}_{4}: 0.05 \mathrm{Eu}^{3+}, 0.1 \mathrm{Sm}^{3+}$ was 3 times higher than that of the single doped phosphor $\mathrm{Sr}_{1.95} \mathrm{CeO}_{4}: 0.05 \mathrm{Eu}^{3+}$. All the results implying that the phosphors $\mathrm{Sr}_{2} \mathrm{CeO}_{4}: \mathrm{Eu}^{3+}, \mathrm{Sm}^{3+}$ has potential research value on white-LEDs.

\section{Acknowledgements}

This work was supported by the National Natural Science Foundations of China (Grant No.51462031 and 21663026), the Gansu Provincial Department of education project (Grant No. 2014B-004), and the introduction of excellent talent Research Funds for the Northwest University for Nationalities (Grant No. xbmuyjrc201125).

\section{References}

[1] H.Y. Jiao and Y. H. Wang, J. Electrochem. Soc., 156 (5) (2009) J117.

[2] T. Liu, Q.Y. Meng and W.J. Sun, J. Lumin., 170(2016)219.

[3] G. Zhu, Y.H. Wang, Q. Wang, X. Ding, W. Y. Geng and Y. R. Shi, J. Lumin., 154 (2014) 246.

[4] [J.Y. Sun, L. Han, Q.G. Xu and Q.M. Di, Ceramics International, 40 (2014) 14261.

[5] Y. Uchida and T. Taguchi, Opt. Eng, 44 (2005) 124003.

[6] J.H. Oh and J.R. Oh, Opt. Expr., 20 (2012) A1.

[7] V. Sivakumar and U.V. Varadaraju, J. Solid State Chem., 181 (2008) 3344.

[8] S. Neeraj, N. Kijima and A.K. Cheetham, Chem. Phys. Lett., 387 (2004) 2 .

[9] L.Y. Zhou, J.S. Wei, F.Z. Gong, J.L. Huang and L.H. Yi, J. Solid State Chem., 181 (2008) 1337.

[10] Y. Liu, G.X. Liu, J.X. Wang, X.T. Dong and W.S. Yu, Inorg. Chem., 53 (2014) 11457.

[11]F.W. Kang, Y.H.Hu, L. Chen, X.J. Wang, H. Y.Wu and Z.F. Mu, J. Lumin., 135 (2013) 113.

[12] H.Y. Jiao, Y.H. Wang and J.C. Zhang, Journal of Physics: Conference Series, 152 (2009) 012089.

[13]Z. L. Wang, H. B. Liang and L. Y. Zhou, J Lumin, 128 (2008) 147.

[14]L.L. Li, Z.H. Leng, W.W. Zi and S.C. Gan, Journal of Electronic Materials, 43(7) (2014)2588.

[15]F. A. Kröger and H. J. Vink, Physica, 20 (1954) 950.

[16] R. Sankar and G. V. Subba Rao, J. Electrochem. Soc., 147 (7) (2000) 2773.

[17] T. Hirai and Y. Kawamura, J. Phys. Chem. B, 108 (2004) 12763. 